\section{Narrow Vs. Broad Measures of Money as Intermediate Targets: Some
Forecast Results}

\section{Michael J. Dueker}

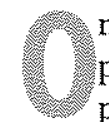

ne of the key challenges of monetary policy is to forecast the links between policy actions and the ultimate objective of stabilizing prices. Measures of the money supply have long been considered links between monetary policy actions and the course of nominal spending and prices. Central banks around the world adopted monetary targets to stop the acceleration of inflation in the 1970s. The strategy worked to end the acceleration of inflation and to lower the inflation rate to moderate levels. The occurrence of high and accelerating inflation, however, triggered financial innovation and deregulation, two processes that seem to have destabilized the income velocity of money. In response, central banks have begun to target their objectives more directly. In some cases, such as New Zealand, Canada and the United Kingdom, they have adopted explicit multi-year targets for inflation. In others, such as the United States, the monetary targets were deemphasized and the de facto policy appears to be something like nominal GDP growth targeting. The question is whether any role remains for intermediate monetary targets.

In the United States, the Federal Reserve uses the interest rate on bank reserves, the federal funds rate, as a guide for supplying bank reserves, so that the monetary aggregates, even the monetary base, are not directly controlled. Here $I$ assume the monetary authority makes policy operational by setting quarterly targets for either nominal spending growth or the rate of inflation. Thus, using a monetary aggregate as an intermediate target implies a multi-stage process that can be diagrammed in the following way:
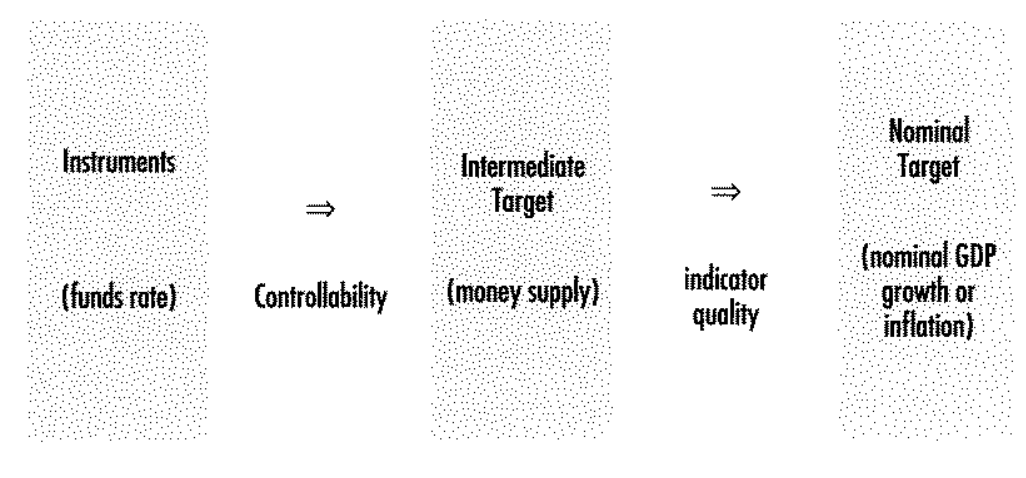

The monetary aggregate used as an intermediate target ideally has two properties: First, the monetary aggregate ought to be controllable in the sense that policymakers know where to set the policy instrument in order to obtain the desired growth in the money supply. Second, it should have a predictable, though not necessarily stable, relationship with the nominal target variable. If the nominal target variable is nominal GDP, then the intermediate monetary aggregate ought to have a predictable velocity. If the target variable is inflation, then the demand for real money balances ought to be predictable.

No intermediate target will be perfect with regard to these two properties. An intermediate target, however, will be a more useful link between policy actions and the nominal target if its errors as an indicator are small and negatively correlated with the errors in controlling it. In other words, the two errors might largely cancel each other on a regular basis, implying that an intermediate monetary target could potentially improve the policy process.

Control error, which results from imprecise policy control over the growth of central bank credit and thereby the money supply 
measures, forces policymakers to forecast the effects of policy actions on the monetary aggregates. The study of control error is not new, although the present analysis brings different statistical techniques to bear. Other empirical studies of monetary control published in this Review include Andersen and Karnosky (1977) and Thornton (1992). In related work, Feldstein and Stock (1993) suggest using $\mathrm{M} 2$ as an intermediate target when the nominal target is nominal GDP. They propose a system of uniform reserve requirements on all $\mathrm{M} 2$ accounts to remedy the control problem. This article, in contrast, explicitly considers control errot as part of monetary policymaking with money as an intermediate target.

Much previous research has focused on the relationships between the monetary aggregates and the path of nominal GDP, that is, their velocities. This research has often sought to determine which aggregates have stable velocities. The implication has been that the best intermediate target is the monetary aggregate with the most stable velocity. For example, based on the apparent long-run stability of M2's velocity from the late 1950 s through the late 1980s, many people viewed it as a reliable nominal anchor (Hallman, Porter and Small, 1991). In the early 1990s, however, M2 velocity increased at a time when its opportunity cost generally decreased by a sufficient amount to raise doubts about the stability of its velocity (Feinman and Porter, 1992; Ritter, 1993).

The comparisons between aggregates in Thornton (1992) also discusses the possibility of opplying reserve requirements across ot M2 accounts.

${ }^{2}$ For a bread survey of potentiol intermediofe doggets for mone tory poticy, including variobles other then monetoyy oggregutes, see Intemediote Torgets and Indicators for Monetany Policy, a putication of the Federal Reserve Bank of Meve Yook.

${ }^{3}$ See Opphanides, Reid and Snall (1994) and Collies and Edwards (1994) for a complete deseription of $192 \div$. his article, on the other hand, focus on the predictability of an aggregate's velocity, not its stability. Furthermore, in the literature on intermediate targeting, the dual problems of monetary control and velocity are acknowledged but they are often addressed separately. This article addresses both jointly in a consistent statistical framework. One caveat, however, is that one time-series forecasting method will be used. Thus, the results are conditional on this method and may be sensitive to changes in the methodology.

This article quantitatively investigates the twin issues of controllability and indicator quality associated with using one of the monetary aggregates as an intermediate target. Restated in concrete terms, the issues are: First, how predictable is the relationship between changes in the funds rate and growth in monetary aggregates? Second, how predictable is the relationship between the monetary aggregates and the nominal targets (nominal GDP growth and inflation)? Third, which monetary aggregate would likely produce the compound forecast error (instruments to money to nominal target) with the smallest variance?

The next section describes the forecasting model used to generate estimates of the error variances in the links between the funds rate, alternative monetary intermediate targets, and two alternative nominal targets: nominal GDP growth and inflation. The third section presents empirical results which consist of one-step-ahead, mean-squared forecast errors for the control error, the velocity error and their sum, the compound error, along with tests for serial correlation. I also perform Bartlet tests for equal variance among the compound errors for the alternative monetary intermediate targets. The fourth section summarizes the results and concludes with policy implications.

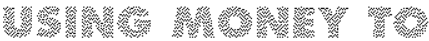

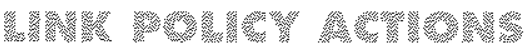

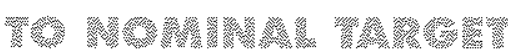

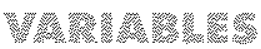

This article includes two sets of results, depending on whether the operational goal of policy is to steer nominal GDP growth or inflation. Of course, long-run inflation will tend to equal long-run nominal GDP growth minus growth in potential real GDP, but in the short run, nominal GDP and inflation may differ in the extent to which they have predictable relationships with the monetary aggregates.

I study four different measures of the money supply as potential intermediate targets: the adjusted monetary base (MB) as calculated by the Board of Governors; M1; M2; and a newer measure called M2-Plus (M2+), which consists of $\mathrm{M} 2$ angmented by bond and equity mutual funds. ${ }^{3}$

In equation 5 below, GDP stands for nominal GDP and $f f$ for the federal funds rate. The rate of nominal GDP growth accompa- 


\section{BFHEY}

nying a given change in the funds rate can be written as the sum of three components: the predicted growth in GDP given predicted growth in the monetary aggregate; the predicted growth in the monetary aggregate given the change in the funds rate; and an overall forecast error:
$\Delta \ln \left(\frac{G D P}{1+f f}\right)$$$
=\Delta \ln \left(\frac{G D P}{M B}\right)_{t \mid-\frac{1}{1}}+\Delta \ln \left(\frac{M B}{1+f f}\right)_{t i-1}+e_{1}
$$

$$
=\Delta \ln \left(\frac{G D P}{M 1}\right)_{t !-1}+\Delta \ln \left(\frac{M 1}{1+f f}\right)_{t ! t-1}+e_{\underline{2 t}}
$$$$
=\Delta \ln \left(\frac{G D P}{M 2}\right)_{t !-1}+\Delta \ln \left(\frac{M 2}{1+f f}\right)_{i t-3}+e_{3 t}
$$$$
=\Delta \ln \left(\frac{G D P}{M 2+}\right)_{t \mid t-1}+\Delta \ln \left(\frac{M 2+}{1+f f}\right)_{t:-1}+e_{t t}
$$$$
=\Delta \ln \left(\frac{G D P}{1+f f}\right)_{t ! l-1}+e_{0,}
$$

whete $t: t-1$ denotes the value forecasted for time $t$ using information available through time $t-1$.

The forecast error in equation $5, c_{0,}$, is based on a direct forecast of the relationship between the funds rate and nominal GDP growth, without reference to an intermediate target. This forecast error will serve as a baseline against which the others, $e_{1 i}, \ldots, e_{4 t}$, are measured, that is, the extent to which an intermediate target reduces the overall or compound error ${ }^{4}$ The forecast errors, $e_{t r} \ldots$, $e_{4}$, are compound errors in that they equal the sum of the velocity forecast error and the control error. For example, for MI

$$
\begin{aligned}
e_{2 f} & =\Delta \ln \left(\frac{G D P}{M l}\right)_{t}-\Delta \ln \left(\frac{G D P}{M 1}\right)_{i \mid t-1} \\
& +\Delta \ln \left(\frac{M 1}{1+f f}\right)_{t}-\Delta \ln \left(\frac{M 1}{1+f f}\right)_{i \mid-1} \\
& =\text { velocity error + control error. }
\end{aligned}
$$

When discussing the results, I use root mean-squared forecast ertor as the criterion in judging, for example, whether $e_{1}$ is large relative to $e_{0}$. The paper also includes analogous comparisons in which inflation, measured by the percentage change in the implicit GDP price dellator, is assumed to be the nominal target of monetary policy. In this case, the price level is substituted for GDP and the error in predicting velocity is replaced with the error in predicting the demand for real balances in equations $1-5$.

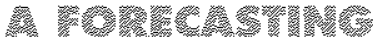

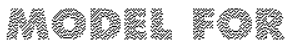

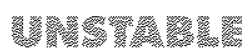

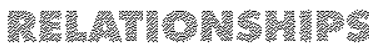

To generate the forecasts needed to estimate the magnitude of the uncertainty from control and velocity error for alternative monetary aggregates, I use two time-varying coefficient models that do not rely on stable relationships for their forecasts: One is for the control relationship between the funds rate and money growth; the other is for the velocity relationship between money growth and growth in the nominal target. Two reasons not to rely on the existence of stable relationships are: (1) M2 velocity, which had been the most stable among the velocities of money, has not appeared stable in recent years; and (2) the relationship between monetary growth and changes in the funds rate almost certainly varies with factors such as the level of intlation, the stage of the business cycle and the degree of credibility of the central bank.

Bernanke (1993) and Eichengreen (1992) argue that the loss of credibility among central banks led to a shift from stabilizing speculative flows in the pre-World War I period to destabilizing speculative attacks in the inter-war period. One implication is that larger policy actions are needed to achieve the same result in the face of destabilizing speculation. Hence, the relationship between the policy instrument and money growth varies with central bank
" Note that all voriobles ore meosured as a percent. 
credibiuty. ln the sample period used in this paper, 1959-94, the credibility of the Federal Reserve probably decreased in the 1970 s when inflation accelerated in contradiction to stated policy objectives. The disinflation of the early 1980s, however, probably enhanced the cred. ibility of the Federal Reserve, because it largely achieved its stated intention of reducing inflation. Moreover, at the statistical level, Dueker (1993) includes test that reject constant-coefficient models of velocity growth in favor of time-varying coefficient models.

I implement a time-varying coefficient (TVC) forecasting model using the Kalman filter. The TVC model allows for heteroskedastic errors, which means the Kalman filter updates the inferred coefficients cautiously when the error variance is high and more liberally when the variance is low. This feature helps the model use the optimal signal-to-noise ratio each period when updating the coefficients and forming next period's forecast.

To keep the forecasting models parsimonious, 1 limit the models to three explanatory variables: quarterly changes in the three-month and to year bond yields and lagged money growth. The changes in the three-month and 10-year rates summarize developments in the yield curve, which varies with the business cycle, and also indicates when asset substitution is likely to occur between short and longmaturity assets. Thus, when forecasting changes in $\mathrm{Ml}$ velocity, for example, the third explanatory variable is lagged Ml growth:

$$
\text { (6) } \begin{aligned}
\Delta \ln \left(\frac{G D P}{M 1}\right)_{t !-1} & =\beta_{0 t}+\beta_{1 t} \Delta \operatorname{TB} 3 m_{t-1} \\
& +\beta_{2 t} \Delta \operatorname{TB} 10 y r_{t-1} \\
& +\beta_{3 t} \Delta \ln M I_{t-1}
\end{aligned}
$$

where TB3mo is the three-month Treasury bill yield, and $T B 10 \mathrm{yr}$ is the constant maturity, 10-year Treasury bond yield. The coefficient on lagged M1 growth, $\beta_{3, \text {, is expected to have }}$ a negative sign because faster money growth does not generally lead to a one-to-one increase in nominal GDP growth immediately. The estimated coefficient tends to be less than unity because some of the stimulus is absorbed by decreases in velocity due to lagged adjustments, and because of time aggregation and other factors. The three-month and 10-year bond yields provide information about the changing opportunity costs of different types of savings accounts by providing infortuation on yield curve spreads.

Similarly, the equation for predicting the relationship between changes in the funds rate and MI growth takes the form

$$
\text { (7) } \begin{aligned}
\Delta \ln \left(\frac{M 1}{1+f f}\right)_{t: t-1} & =\beta_{0 !}+\beta_{11} \Delta \Gamma B 3 m o_{t-l} \\
& +\beta_{2,} \Delta T B 10 y r_{t-1} \\
& +\beta_{3 \mathrm{r}} \Delta \ln M 1_{t-1} .
\end{aligned}
$$

The coefficients on the lagged short and long-term interest rates are both expected to be negative, because higher interest rates at all points along the yield curve will generally be associated with a higher funds rate and lower Ml growth. The coefficient on lagged Ml growth, on the other hand, does not have a clearly implied sign. When policy is geared toward disinflation, high MI growth in the last period can portend substantial increases in the funds rate, implying decreases in the $\mathrm{Ml} /$ funds rate ratio. When nominal interest rates are relatively stable, however, positive serial correlation in $\mathrm{Ml}$ growth rates can imply a positive coefficient.

The accompanying box contains plots of the time-varying coefficients for the M1 equations to illustrate the changes in relationships between variables in the sample period. Further details on the forecasting model are also in the appendix and in Kim (1993).

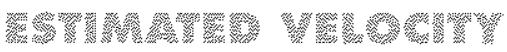

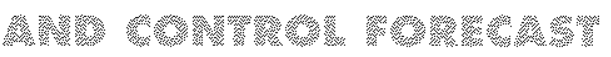

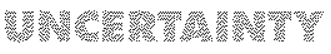

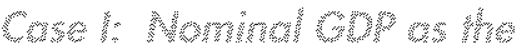

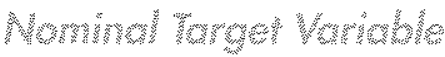

Table 1 contains results for nominal GDP growth, including four cases with alternative intermediate monetary targets and one in which no intermediate target is employed. Control error refers to the error in predicting 


\section{Changes in Time-Varying Coefficients}

Figures 1-4 illustrate the changes in the coefficients on the variables explaining the growth in Ml velocity over time. The financial deregulation of the late 1970 s and early 1980 s appears to have brought structural change to $\mathrm{Ml}$ velocity that was only partially undone when the inflation rate stabilized in the mid-1980s. The drift in Ml velocity was steady until the late 1970 s, when it decreased, never to return to its 3 percent annual upward trend of the 1960s and 1970s. The response of Ml velocity to changes in the three-month $\mathrm{T}$-bill rate, for example, declined in an irregular pattern until the early $1980 \mathrm{~s}$ when checkable deposits began paying interest. The response of $M l$ velocity to changes in the 10-year Treasury bond rate, on the other hand, has generally trended upward from the beginning of the sample period until the late 1970s. Since then it has been lluctuating around a positive value. The coefficient on lagged MI growth is negative and stggests that high M1 growth today will lead to decreased velocity next quarter, although this elasticity was near zero when inflation was high in the late 1970 s and early 1980 s.

Figures 5-8 illustrate the estimated changes in the coefficients from equation 7. In general, the coefficients underwent relatively large changes or changes in their trend around the time the inflation rate was stabilized in the mid-1980s. In the late 1960 s and 1970 s, inflation gradually accelerated, and in the late 1970 s and early 1980 s disinflation occurred until the inflation rate stabilized at an annual rate of roughly 3 or 4 percent. The drift or intercept term in Figure 5 shows an upward trend until intlation stabilized and then decreased dramatically before resuming an upward trend again. The coefficients on the short-and long-term interest rates are negative as expected. The coefficient on the short rate, shown in Figure 6, became less negative until the mid-1980s, when it became more negative than in the $1960 \mathrm{~s}$. The response of the $\mathrm{M} 1$-federal funds rate ratio became more negative from the beginning of the sample period through the late 1980s. The coefficient on lagged M1 growth shifted from positive in the 1960 s to negative during the period of high and volatile interest rates, and then became positive and larger as inflation and interest rates declined.

the relationship between the funds rate and money growth. Velocity etror stems from the uncertain link between money growth and nominal GDP growth. Summing the ertors yields the compound error. Moving across columns in Table 1, we start with control error.

In the first column, we see that natrower measures of money are generally more controllable than broader ones. The Q statistics in parentheses indicate whether the forecast errors displayed significant serial correlation. The $\chi_{2+}^{2}$ critical value is 36.4 , which is exceeded only by the control error for the base. With this lone exception, however, the $Q$ statistics are not significant in the control errors, the velocity errors or the compound errors in Table 1, so the forecasting models almost uniformly generate forecast errors which are not significantly serially correlated.
In the second column, the uncertainty in velocity is apparently not directly linked to the narrowness of the monetary aggregate. The base, $\mathrm{Ml}$ and $\mathrm{M} 2$ have very similar degrees of uncertainty in velociry. Hence, even though base and MI velocity are not as stable as $M 2$ velocity, they are roughly as predictable. In the the third column, the uncertainty in the compound errors indicates that the variance of the sum is uniformly less than the sum of the variances, which implies that the covariances between control and velocity errors are negative. Ml has the lowest RMSE in the compound error, but is closely followed by the null choice of no intermediate target and the monetary base. To test whether the forecast error variance for MI is significantly lower than the variances associated with the other measures, I performed Bartlett tests for equal variances
5 repot results from $1964: 01$ through 1993:04 even though the sample stats in 1959:03. becouse sevend endy obseryo. tions ore set aside to initilize the Kotmon filter. 


\section{Drift Term in MI Velocity Growth Equation}

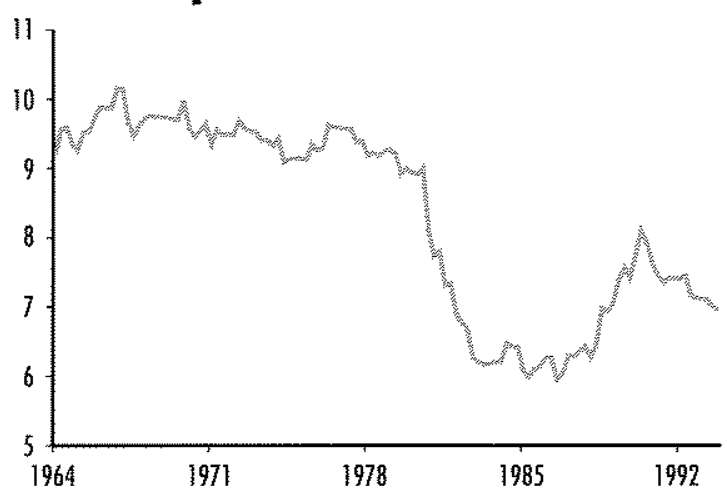

\section{Effect of Lagged Change in 10-Year T-Bond Yield on} Growth in M1 Velocity

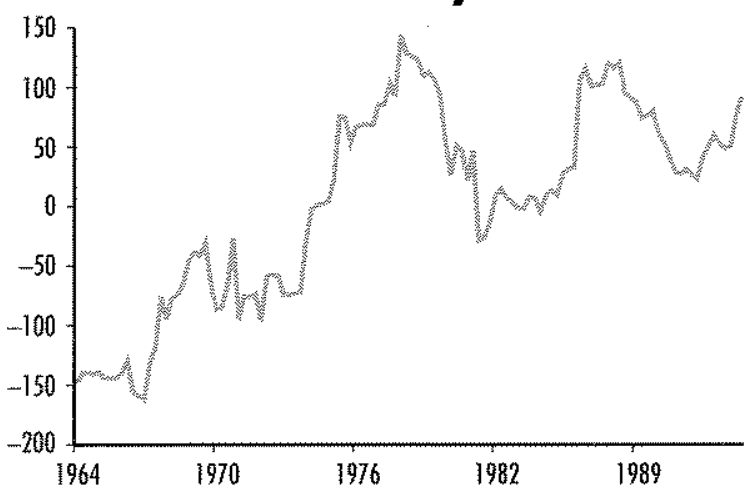

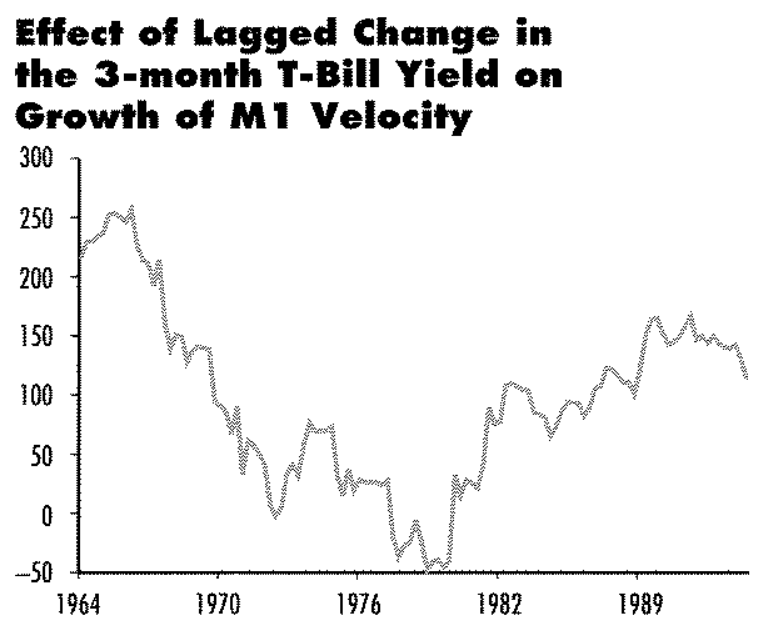

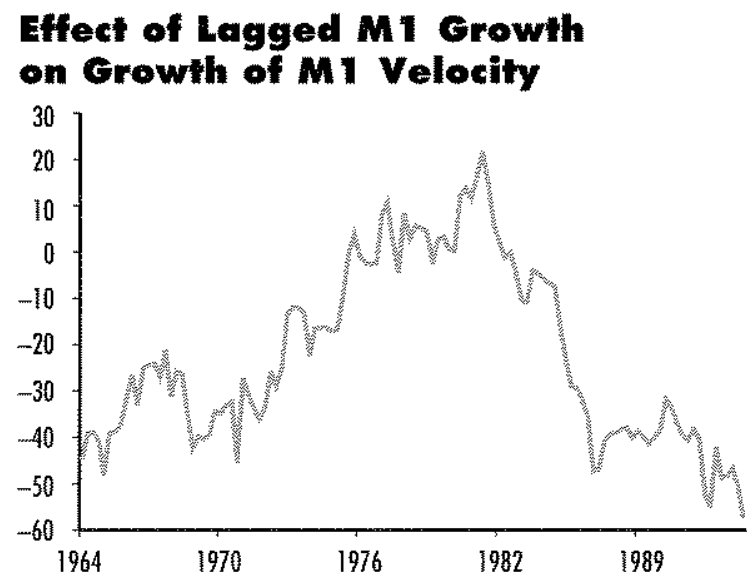

across the compound errors. $\mathrm{M} 2+$ had the highest test statistic of 0.064 , but this is still well below the $\chi_{3}^{2}$ critical value of $3,8 . \mathrm{Ml}$ has the lowest compound forecast error variance in the links between monetary policy actions and nominal GDP growth, but the other monetary aggregates have variances that are not significantly higher.

Since this exercise was conducted with quarterly data, however, this method of calculating the compound forecast errors may overstate control errors, becaluse data on reserves, the base and monetary aggregates are available on a weekly basis. Within each quarter, policymakers could change the funds rate in response to any emerging control error to try to hit the end-of-quarter monetary target. In practice, however, the Fed seeks to mitigate excess volatility in short-term interest rates (Bryant, 1983). Thus, the claim that weekly money-supply data would allow the achievement of zero control ertor is not realistic either. The true degree of uncertainty lies somewhere between the control errors reported here and zero. Moreover, the ability of policy to respond to intra-quarter developments in money growth is difficult to quantify, given curment Federal Open Market Commituee (FOMC) procedures for changing the funds 
Drift Term in the Relationship Between the Federal Funds Rate and $M I$ Growth

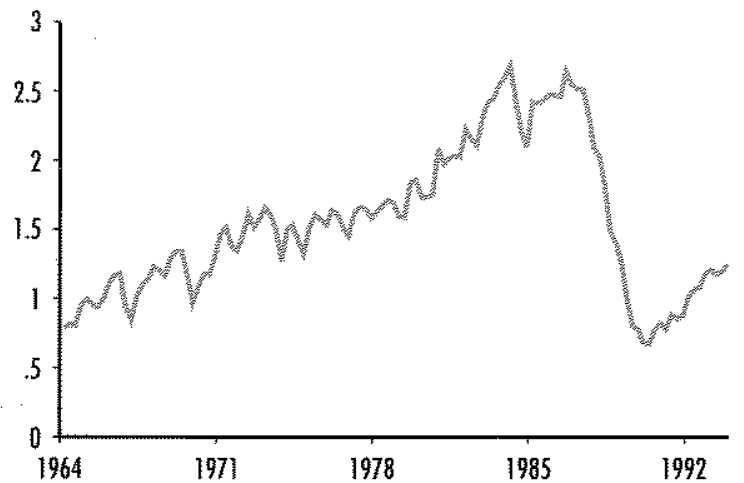

Effect of Lagged Change in the 10-year T-Bond Yield in Predicting the Relationship Between the Federal Funds Rate and MI Growth

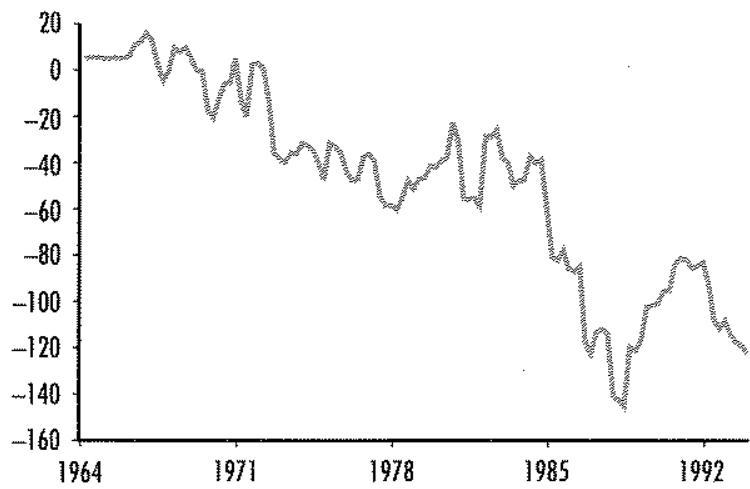

Effect of Lagged Change in the 3-Month T-Bill Yield in Predieting the Relationship Between the Federal Funds Rate and $M 1$ Crowth

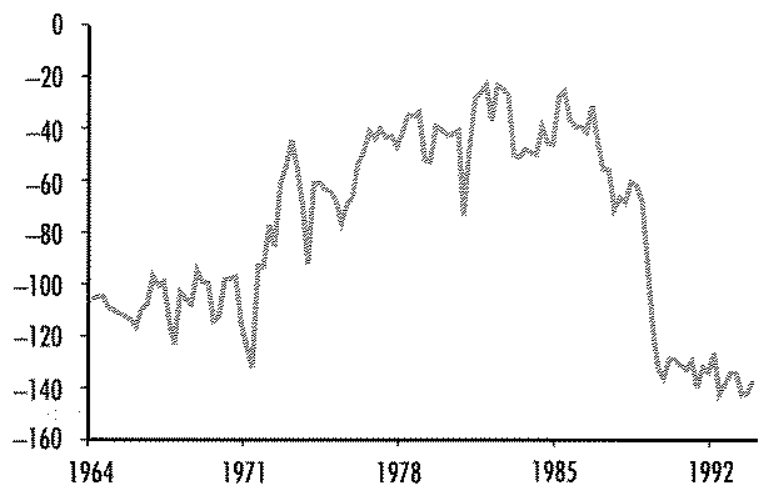

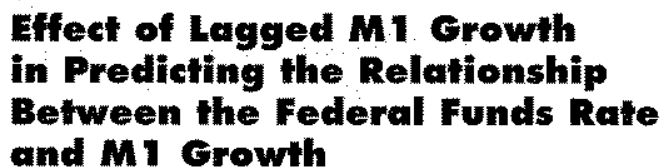

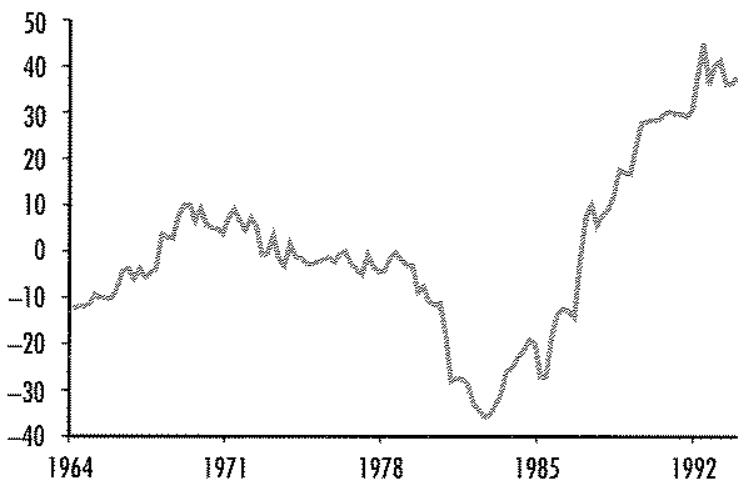

rate between regular meetings, which take place every six to eight weeks. Any attempt to adjust the estimated control errors for intra-quarter funds rate adjustments is beyond the scope of this study.

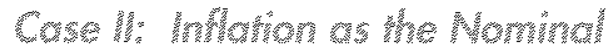

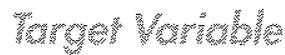

This section performs analogous, but not directly comparable, analysis of potential internediate targets under the assumption that the rate of inflation is the nominal policy target. When inflation is the ultimate objective, it is necessary to forecast growth in the price level/money supply ratio (the negative of the growth rate of real balances), rather than velocity growth. The control errors are unaffected as we change the nominal target variable objective, except for the control error resulting from targeting the inflation rate directly from the federal funds rate, that is, with no intermediate target. With this exception, the first column in Table 2 is the same as in Table 1.

In the analysis of Table 2 , we begin in the second column by noting that the base and M2 have the most predictable relationships with inflation. Ml has somewhat higher real balances error, but still achieves the lowest 


\section{(2)}

Intermediale Targetry Comparison (nominal target: nominal GDP; policy instrument: federal funds rate)

Root Mean-Squared Forectst Errors (RMSE)

\begin{tabular}{|c|c|c|c|}
\hline $\begin{array}{l}\text { Monetary } \\
\text { Aggregate }\end{array}$ & $\begin{array}{l}\text { Control } \\
\text { Error }\end{array}$ & $\begin{array}{l}\text { Velocity } \\
\text { Errer }\end{array}$ & $\begin{array}{l}\text { Compound } \\
\text { Error }\end{array}$ \\
\hline Ilonet & $\begin{array}{l}1.467 \\
(2370)\end{array}$ & $\mathrm{no}$ & $\begin{array}{r}1467 \\
2370)\end{array}$ \\
\hline Base & $\begin{array}{r}171 \\
(40 \% 5)\end{array}$ & $\begin{array}{l}1,03 \\
1701)\end{array}$ & $\begin{array}{r}1,483 \\
(26.68)\end{array}$ \\
\hline $\mathbb{N}$ & $\begin{array}{r}1349 \\
12555)\end{array}$ & $\begin{array}{r}1122 \\
24851\end{array}$ & $\begin{array}{r}1,450 \\
(22.27)\end{array}$ \\
\hline 12 & $\begin{array}{r}1647 \\
(3135)\end{array}$ & $\begin{array}{r}1 / 21 \\
20,681\end{array}$ & $\begin{array}{r}1529 \\
(30,851\end{array}$ \\
\hline M21 & $\begin{array}{r}1771 \\
(3198)\end{array}$ & $\begin{array}{r}1,305 \\
20.86\end{array}$ & $\begin{array}{r}1539 \\
(2953)\end{array}$ \\
\hline
\end{tabular}

* Direct forecasts of GDP/tunds rote relotionship

Notes: Mean-squared forecast efror (MSFE) for compound error is not equal io sum of MSFEs dise to covariances between errors. Time periad: 1964:01-1993:04. Q statistic for serin correlation in perentheses: 5 percent critical value with 24 degrees of freedom is 36.4

compound RMSE, shown in the third column, due to negative correlation between the control and real balances errors. The root mean square of the compound errors of $\mathrm{M} 2$ and $\mathrm{M} 2+$ are only slightly larger than for $\mathrm{Ml}$, but they are significantly serially correlated, as indicated by the statistics. As with the nominal GDP results, the Bardett tests for differences in compound forecast error variances prove to be rather weak; once again, the test failed to reject the hypothesis that the other monetary aggregates had the same compound forecast error variance as Ml. The monetary base had the highest Bartlett test statistic of 0.62 , which was nonetheless below the $\chi_{1}^{2}$ critical value of 3.8 . As with nominal GDP. MI has the lowest compound forecast error variance in the links between monetary policy actions and inlation, but the other monetary aggregates have variances that are not significantly higher.

\begin{tabular}{|c|c|c|c|}
\hline \multicolumn{4}{|c|}{$\begin{array}{l}\text { Intermediete Targelry Comparison } \\
\text { (nominal target: inflation; policy instrument: federal funds rate) }\end{array}$} \\
\hline \multirow[b]{2}{*}{$\begin{array}{l}\text { Monetury } \\
\text { Aggregute }\end{array}$} & \multicolumn{3}{|c|}{ Root Mean-Squared forecost Errors (RMSE) } \\
\hline & $\begin{array}{l}\text { Control } \\
\text { Error }\end{array}$ & $\begin{array}{l}\text { Real Balances } \\
\text { Error }\end{array}$ & $\begin{array}{l}\text { Compound } \\
\text { Error }\end{array}$ \\
\hline None* & $\begin{array}{r}1393 \\
(33.01)\end{array}$ & no. & $\begin{array}{l}1,393 \\
13301)\end{array}$ \\
\hline Base & $\begin{array}{r}1,171 \\
(40.95)\end{array}$ & $\begin{array}{r}0.489 \\
(17.41)\end{array}$ & $\begin{array}{l}1.447 \\
(28.32)\end{array}$ \\
\hline n & $\begin{array}{r}1.349 \\
(25.55)\end{array}$ & $\begin{array}{r}0.710 \\
019.867\end{array}$ & (29:12) \\
\hline M2. & $\begin{array}{r}1.647 \\
(31.35)\end{array}$ & 0.463 & 1.290 \\
\hline M2 & $\begin{array}{r}171) \\
(3198)\end{array}$ & 0.644 & $\begin{array}{l}1,272 \\
(38.21)\end{array}$ \\
\hline
\end{tabular}

${ }^{*}$ Direct forectsts of inflation/tunds rote relationship

Hotes: Mean-squared foreccist error (MSFE) for compound error is not equal to sum of MSFEs due to covariances between errors. Time period: 1964:01-1993:04. Q siatistir for serial corralotion in parentheses: 5 percent crifical value with 24 degrees of freedom is 36.4

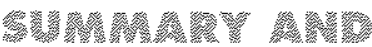

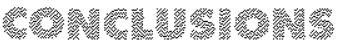

This article has shown that the errors in predicting the effect of policy actionssummarized by changes in the federal funds rate-on the growth of potential internediate monetary targets (control errors) are often as large or larger than the error in predieting changes in the velocities of the monetary aggregates (velocily error). Thus, control error, an often-neglected dimension of using money as an intermediate target, appears to be of roughly equal concern as velocity error in evaluating alternative monetary aggregates as intermediate targets.

With respect to the question of whether to use M1 or M2 as an intemediate target, I find that, when accounting for both control and velocity error, $\mathrm{M} 1$ and $\mathrm{M} 2$ achieve compound fotecast etrors that are not significantly different from each other, whether nominal 
GDP or inflation is the assumed nominal target variable. One obvious question, however, is whether the use of a monetary intermediate target offers any advantages relative to forecasting directly the effects of policy actions on the nominal policy target-nominal GDP growh or inflation. $\mathrm{Ml}$ is the only monetary aggregate with RMSEs uniformly lower than the RMSEs associated with direct forecasts of the relationships between the funds rate and both nominal GDP growth and inflation. Bartlett tests for equality of forecast error variances fail to find a statistically significant difference between the forecast error variances, however. Thus, the evidence in favor of using an intermediate target variable is not decisive.

The emphasis on control error in this article also serves to remind market participants that recent growth rates in the monetary aggregates do not necessarily represent the thrust of monetary policy, given that control and velocity errors are generally negatively correlated. Thus, control error introduces a potentially large difference between the rate at which the money supply is actually growing and the rate of effective or velocity-adjusted money growth. Thus, at times when observers have expressed concern about unusually fast or slow M2 growth, for example, it is likely that control error was responsible for much of the anomaly. Figure 9 illustrates this point by plotting the difference between actual M2 growth and the growth that would have taken place if there had been no control error, that is, if $\mathrm{M} 2$ had turned out as predicted. Figure 9 shows the relationships between predicted and actual M2 quarterly growth rates and inflation. In the late 1970 s and early 1980 s, predicted M2 growth signalled a tightening of monetary policy that preceded the disinflation of the early 1980s, whereas actual M2 gave no such signal. An increase in predicted M2 growth in the mid 1980 s also indicated that the inflation rate would stop falling. Actual M2 growth rates, on the other hand, continued to decrease. In the early 1990s, predicted M2 growth has been consistently stronger than actual M2 growth, indicating that the inflation rate would not continue falling toward zero, as some analysts projected.

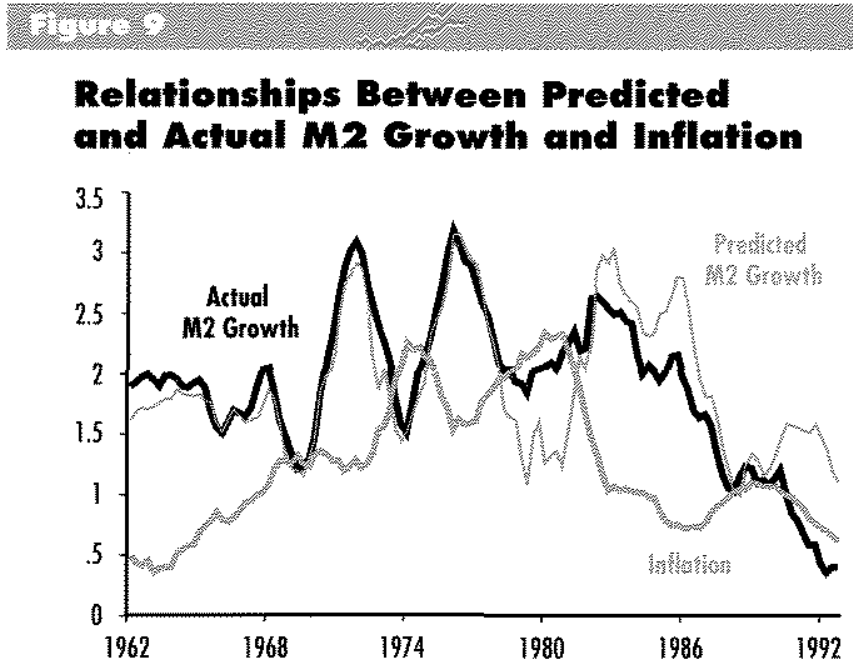

\section{-}

\section{Actual and Predicted M2 Growth and the FoMc's Target Range}

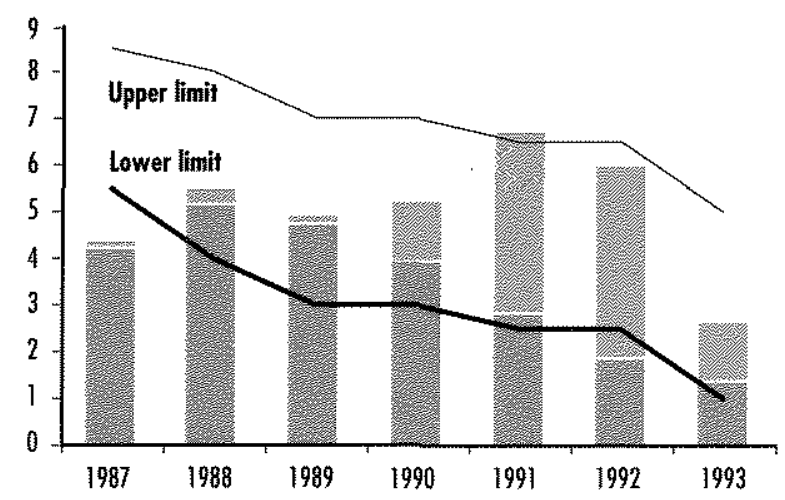

Figure 10 highlights the effect of M2 control errors on the latter part of the sample period. The graph includes the upper and lower limits for the FOMC's announced M2 growth targets along with actual M2 growth and what M2 growth would have been absent control error. The chart shows that in 1991-93, M2 growth adjusted for control error was near the upper range of the FOMC target range, as opposed to actual $\mathrm{M} 2$, which languished near the bottom of the target range. The former was suggestive of the relatively strong economic recovery that developed in 1994, whereas actual M2 growth was not. Thus, adjusting $M 2$ growth for the control errors can often provide a better policy indicator than the unadjusted data, which 
can make policy appear more inflationary or disinflationary than it is.

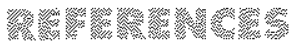

Andersen, Leonoll C, and Dennis S. Kanosky. "Some Considerotions in the Use of Monetory Aggregates for the Implementation of Monetary Pollcy, "hitis Review (Septembez 1977), pp. 27.

Belongia, Michoel T., and Ondlas 5 . Batten. "Selecting an Infermedote Target for Menetary Poicy when the God is Price Stobility, Federd Reserve Bank of St. Louis Working Poper No. 92-008A (0tober 1992)

Bennanke, Ben 5. "The World on a Cross of Gold: A Review of Golten Fetters: The Gold Standord and the Geent Depression, 1919-1939," Jound of Monetry Economics (April 1993), pp. 251.67.

Bryont, Rolph C. Controling Money: The Federd Reserve and its Critics. The Brookings snstitution, 1983.

Colins, Sean, and Cheryl L. Edwards. "An Alternotive Monetory Aggregate: M2 Plus Household Holdings of Bonte and Equily Muteal Funds," this Review (Hovember/December 1994), pp. 7-29.

Dueker, Michool I. "Can Nominal Gepp Targeting Rutes Stabilize the Econony?" this Review (May/June 1993), pp. 15-29.

Edchengreen, Bary. Golden Fefters: The Gold Stondord and the Great Depression, 7919-193\%. Oxtort University Press, 1992

Federal leserve Bank of liew York. Intermediate Targets and Indicofors for Manetary Policy (A Criticol Survew), stly 990.
Feinmen, Joshuo N., and Ruthodd D. Porter. "The Continuing Weakness in $M 2, "$ Finance and Economics Discussion Series Working Paper No. 209, Board of Governors of the Federal Reserve System (September 1992).

Feldstein, Martin, and Jomes H. Stack. "The lise of Monetoy Aggregate to Torget Noringl GDP," NBER Working Poper No. 4304 (March 1993).

Hattmon, Jeffeey J., Richard D. Parter and Devit H. Small. "Is the Price Lavel lied to the M2 Aggregote in the Long Run?," Anericon Econonic Review (September 1991), pp. 841-58.

Kim, Chong-tin. "Dynamic Linear Modes will Markow-Switching," Jound of Econometrits (Jonuar/February 1994), pp. 1-22.

"Sources of Honetary Growth Uncertainty ond Economic Activity: The Tine-Vonying Porameter Model with Heteroskedastic Dishobonces," The Review of Economics and Statistics (August 1993), pp. 483-92.

Ophonides, Athonasias, Brian Reid and David H. Small. "The Empirical Propeties of a Monetery Aggregates That Adds Bond and Stock Funds to M2," this Review (November/December 1994), pp. 31-51.

Ritter, Joseph A. "The FOAC in 1992: A Monetory Conendrum," this Review (Moy/lune 1993), pp. 31-49.

Thonton, Danitel L. "Iorgetiong M2. The issue of Monetary Control," this Review (Auly/August 1992), pp. 23-35. 
TIME-VARYING COEFFICIENTS

The time-varying coefficient model that generates the short-run forecasts is

$$
\begin{aligned}
& y_{t}=X_{t-1} \beta_{t}+e_{t} \\
& \beta_{t}=\beta_{t-1}+v_{t} \\
& v_{t} \sim \operatorname{Normal}(0, \boldsymbol{O}),
\end{aligned}
$$

where $y$ is the dependent variable and $X_{t-1}$ is a vector of explanatory variables. With time-varying coefficients, equation 1 (in the first section) will be estimated using the Kalman filter under the assumption that the state variables, $\beta_{l}$, follow random walks. In a short-run forecasting context, the assumption that the coefficients follow random walks suggests that people need new information in order to change their view about the relationships among variables. The innovations, 0, to the coefficients are assumed to be uncorrelated, so the covariance matrix $Q$ is diagonal.

The errors in equation $1, e_{t}$, have timevarying volatilities in that their variance is assumed to switch between a low and high level according to a first-order Markov process.'

$$
\begin{gathered}
e_{t} \sim \operatorname{Normal}\left(0, h_{t}\right) \\
h_{t}=\sigma_{0}^{2}+\left(\sigma_{1}^{2}-\sigma_{0}^{2}\right) S_{t} \\
S_{t} \in\{0,1\} \\
\sigma_{1}^{2}>\sigma_{0}^{2} \\
\text { Probability }\left(S_{t}=1 \mid S_{t-1}=1\right)=p \\
\operatorname{Probability}\left(S_{t}=0 \mid S_{t-1}=0\right)=q .
\end{gathered}
$$

By construction, this model allows for two sources of forecast error: error in predicting the value of the coefficients and the heteroskedastic random disturbance. ${ }^{2}$ In a model with time-varying coefficients,

$$
y_{t}=X_{i-1} \beta_{t}+e_{t},
$$

and the one-step-ahead forecasts are

$$
y_{t \mid c-1}=X_{t w 1} \beta_{t \mid[-1} .
$$

Thus, the forecast errors have two components and equal

$$
X_{t-1}\left(\beta_{\imath}-\beta_{t \mid t-1}\right)+e_{\imath} .
$$

If the variance of

$$
\left(\beta_{\ddagger}-\beta_{t \mid t-1}\right) \equiv R_{t \mid t-1} \text { and } \operatorname{var}\left(e_{t}\right) \equiv \sigma_{*}^{2},
$$

the one-step-ahead forecast error variance is

(5) $H_{t} \equiv H_{1 t}+H_{2 t}=X_{t-1} R_{t \mid \mathrm{t}-1} X_{t-1}^{\prime}+\sigma_{\mathrm{t}}^{2}$.

The frrst component $\left(H_{l l}\right)$ is called the variance due to time-varying parameters (TVP); the second $\left(H_{2 t}\right)$ is simply the variance of the random disturbance, $e_{t}$. Inferences regarding the relative sizes of the two sources of forecast error variance play an important role in updating the coefficients. Using the Kalman filtering equations, it can be shown that the forecast $y_{i+1 \mid t}$ can be written as

$$
y_{t+1 \mid t}=X_{t} \beta_{t \mid t-1}+Z_{t} \eta_{t \mid t-1}
$$

where $X_{t}$ are the explanatory variables, $\eta_{t-1}$ is last period's forecast error (and is thus the new information available), and $Z_{i}$ is proportional to

$$
\frac{H_{1 t}}{H_{1 !}+H_{2 i}} .
$$

If $H_{2 t}$ is large relative to $H_{1 b}$, observers would attribute less of a forecast error to a change in coefficients; rather, they would believe that it was likely to have been an outlier. A large value of $H_{2 t}$ then implies that last period's forecast error will play a relatively small role in determining next period's forecast.
Futher details on tine-varying coefficient models with hoteroskedastic erross are in $\operatorname{tim}$ (1993).

${ }^{2}$ Kim (1993) discusses the specific form the Kaman filter rakes for this model and the evaluation of the likelihood function, wheth is moximized with respect to $\left(\sigma_{0}^{2}, \sigma_{1}^{2}, p\right.$, $q, Q$, where $a_{i j}=\sigma_{i j}^{2}$. 